\title{
A HYDRODYNAMIC MODEL FOR FLIGHTED ROTARY KILNS \\ USED FOR THE CONVERSION OF COHESIVE URANIUM POWDERS
}

Marie DEBACQ ${ }^{\mathrm{a}, \mathrm{b}, 1}$, Phahath THAMMAVONG ${ }^{\mathrm{c}}$, Stéphane VITU ${ }^{\mathrm{c}}$, Denis ABLITZER ${ }^{\mathrm{a}}$, Jean-Léon HOUZELOT $^{\mathrm{b}}$, Fabrice PATISSON ${ }^{\mathrm{a}}$

${ }^{a}$ Institut Jean Lamour (UMR 7198) - Département Science et Ingénierie des Matériaux et Métallurgie

(SI2M), École des Mines de Nancy, Parc de Saurupt, CS 14234, 54042 Nancy cedex, France

${ }^{\mathrm{b}}$ Laboratoire de Réactions et Génie des Procédés (UPR 3349), École nationale supérieure des industries chimiques (Ensic), 1 rue Grandville, BP 20451, 54001 Nancy cedex, France

${ }^{c}$ Laboratoire de Génie des Procédés pour l'Environnement, l'Énergie et la Santé (EA 21), Conservatoire National des Arts et Métiers (Cnam), case 2D1P20, 292 rue Saint-Martin, 75141 Paris cedex 03, France

DOI: 10.1016/j.ces.2013.09.037

Chemical Engineering Science 104 (2013) 586-595

\section{Corresponding author}

Dr. Marie DEBACQ (marie.debacq@ cnam.fr), Laboratoire de Génie des Procédés pour l'Environnement, l'Énergie et la Santé (EA21), Cnam, case courrier 2D1P20, 2 rue Conté, 75003 Paris, France. +33 15880 8707

\begin{abstract}
The axial and transverse solid distribution of a cohesive powder in flighted rotary kilns was calculated from an original method based on the lifter discharge law previously determined, geometrical calculations and supplementary measurements (in particular the fall velocity of the powder at high temperature). At a given axial position, the quantity of powder falling through the gas, the total quantity of flighted powder as well as the quantity remaining in the bulk are thus calculated; the axial bed depth profile is obtained from the Saeman-Kramers-Afacan model.
\end{abstract}

\section{Highlights}

- Transverse flow of cohesive powder in flighted rotary kiln was modelled.

- Axial bed depth profile was calculated from Saeman-Kramers-Afacan model.

- Solid distribution was calculated from geometrical calculations and measurements.

- The fall velocity of the cohesive powder was measured at high temperature.

- The 'snapshot' obtained allows to calculate thermal transfer areas and mass transfer.

\section{Keywords}

rotating cylinder; cohesive powder; lifter; transverse distribution; hydrodynamics; uranium

\footnotetext{
${ }^{1}$ Present address: Laboratoire de Génie des Procédés pour l'Environnement, l'Énergie et la Santé (EA 21), Conservatoire National des Arts et Métiers (Cnam), case 2D1P20, 292 rue Saint-Martin, 75141 Paris cedex 03, France
} 


\section{INTRODUCTION}

For over a century (Meade, 1914), rotary kilns have been widely used in the inorganic chemical industry. They are a key element in the production processes of cement (Mujumdar and Ranade, 2006), lime and pigments (titanium dioxide calcination) and in extractive metallurgy for the reduction of ore (Boateng, 2008). Rotary kilns are well suited for the conversion of coal and coke (Lebas et al., 1995), for drying (Shahhosseini et al., 2000), for the pyrolysis of solid waste (Descoins et al., 2005; Marias et al., 2005), and are also used for several conversions in the manufacture of nuclear fuel (Debacq, 2001; Thammavong et al., 2011).

Rotary kilns used for the conversion of enriched or depleted uranium are equipped with lifters and are externally and electrically heated, but they differ in size and nominal operating conditions, as can be seen in Table 1: the type of rotary kiln used for depleted uranium conversion is henceforth named "kiln \#1"; the type of conversion kiln used for enriched uranium is named "kiln \#2". In these rotary kilns, uranyl difluoride $\left(\mathrm{UO}_{2} \mathrm{~F}_{2}\right)$ is converted into uranium oxides: $\mathrm{U}_{3} \mathrm{O}_{8}$ in the case of depleted uranium in kiln \#1; $\mathrm{UO}_{2}$ in the case of enriched uranium in kiln $\# 2\left(\mathrm{U}_{3} \mathrm{O}_{8}\right.$ is an intermediate during the conversion from $\mathrm{UO}_{2} \mathrm{~F}_{2}$ to $\mathrm{UO}_{2}$ ).

In this type of rotary kilns, heat and mass transfer are strongly governed by hydrodynamics, which determines -among other characteristics- the quality and duration of gas/solid contact. In order to correctly model the operation of the conversion kilns, it is essential to be able to calculate precisely the solid distribution at any point in the rotary kiln.

While there is an abundant literature on the hydrodynamics of unflighted rotary kilns (see for example Henein et al., 1983; or Mellmann, 2001), only a few studies concern flighted rotary kilns (see for example Van Puyvelde, 2009). The hydrodynamics can be studied globally: the effect of lifters on the total hold-up (see for example Friedman and Marshall, 1949), the time of passage (see for example Prutton et al., 1942), or the mean residence time (see for example Britton et al., 2006). A few studies propose calculation of the amount of powder falling through the gas (sometimes called airborne solid), usually in rotary dryers fitted with a large number of lifters (often a dozen, and in some cases several dozen), in which this amount is high. In such cases, it is not worth taking into account the variation of the bulk depth at the bottom of the rotary kiln with the axial position, and the calculated length of particle fall depends solely on the angular position (see for example Fernandes et al., 2009). Moreover, the total flighted powder fraction is mostly not calculated since, in the case of drying with hot gas circulating through the rotary kiln, the solid in the flights plays practically no role in the drying and heating processes. Thus, in these studies, only airborne (and sometimes dense phase hold-up) is quantified (Schofield and Glikin, 1962; Matchett and Baker, 1987, 1988; Sherritt et al. 1993, 1994; Wang et al., 1995; Ajayi and Sheehan, 2012a, 2012b).

In the rotary kilns studied here, the number of lifters is much lower than in dryers ( 4 or 6 depending on the type of conversion kiln). A substantial amount of solid may therefore remain in the bulk; the quantity of powder falling through the gas is extremely small (although it plays a very important role in the chemical reaction) and the solid in the lifters is likely to react and to play a role in the thermal exchanges with the wall which is externally heated. It has therefore been necessary to develop a novel model to quantify the various amounts of solid.

In a previous study (Debacq et al., 2013), the discharge law of cohesive powders in flighted rotary kilns was obtained both experimentally and theoretically (i.e. from geometrical considerations), including high temperature measurements. Sunkara et al. (2013a, 2013b) published a similar method for the calculation of the discharge characteristics of rectangular flights, but with experiments on non-cohesive particles and at room temperature.

In the present study a model is proposed to calculate the transverse solid distribution in a flighted rotary kiln; this model takes into account the change in the bulk density and therefore in the volumetric flow rate of the solid induced by the chemical reactions. The transverse solid distribution can be calculated by applying the lifter discharge law: for each axial position in the conversion kiln, a 'snapshot' can be determined, representative of the powder fraction $\eta_{\mathrm{F}}$ in the lifters, the powder fraction $\eta_{\mathrm{G}}$ falling through the gas and the powder fraction $\eta_{\text {в }}$ in the bulk (Fig. 0 / Graphical abstract). This is particularly useful to 
study mass transfer between these different powder fractions and gaseous reagents. This 'snapshot' also makes it possible to calculate all the thermal transfer areas, such as the area between solid and wall or between solid and gas, etc.

\section{HYDRODYNAMIC MODEL}

\subsection{Axial profile of bed depth}

The axial profile of the bed depth (h versus $\mathrm{x}$ ) was calculated using laws available in the literature: the bed depth at different axial positions along rotary kilns without inserts in rolling mode can be calculated from the differential equation (1), proposed by Saeman (1951), Vàhl and Kingma (1952) and Kramers and Croockewit (1952):

$$
\frac{\mathrm{dh}}{\mathrm{dx}}=\frac{\tan \alpha}{\cos \theta}-\frac{3 \cdot \mathrm{Q}_{\mathrm{V}} \cdot \tan \theta}{4 \pi \cdot \omega \cdot \mathrm{R}^{3}} \cdot\left[\frac{2 \cdot \mathrm{h}}{\mathrm{R}}-\left(\frac{\mathrm{h}}{\mathrm{R}}\right)^{2}\right]^{-3 / 2}
$$

From observations made in the pilot plant described previously (Thammavong et al., 2011), the presence of a small number of lifters does not modify the shape of the bed depth profile proposed by Saeman.

As suggested by Afacan and Masliyah (1990), the numerical solution of the differential equation (1) can be found using a fourth-order Runge-Kutta method. These authors also suggested using a bed depth equal to the height of a lifter plus twice the diameter of the particles $\left(h_{p}+2 . d_{p}\right)$ as the boundary condition at the cylinder exit. More recently Specht et al. (2001) found in smooth rotary kilns (without lifters or dam) that the solid depth at the discharge is several times higher than the particle diameter (and not only twice as high, as suggested by Afacan and Masliyah, 1990). Since the particles studied here are very small (Table 2), their size is negligible compared to the height of a lifter (Table 1); after conducting tests, it appeared unnecessary to take their size into account in the boundary condition, thus only $h_{p}$ is used.

The local kiln hold-up $\mathrm{Z}(\mathrm{x})$ for each axial position $\mathrm{x}$ can be calculated using relation (2) from the local bed depth $\mathrm{h}(\mathrm{x})$ obtained by integrating the differential equation (1) using a fourth-order Runge-Kutta method.

$$
\mathrm{Z}(\mathrm{x})=\frac{\cos ^{-1}\left(1-\frac{\mathrm{h}(\mathrm{x})}{\mathrm{R}}\right)-\left(1-\frac{\mathrm{h}(\mathrm{x})}{\mathrm{R}}\right) \cdot\left(2 \cdot \frac{\mathrm{h}(\mathrm{x})}{\mathrm{R}}-\left(\frac{\mathrm{h}(\mathrm{x})}{\mathrm{R}}\right)^{2}\right)^{1 / 2}}{\pi}
$$

In the case studied here, the volumetric flow rate $\mathrm{Q}_{\mathrm{v}}$ is not constant since the bulk density of the solid changes considerably during its conversion along the cylinder, going from $\mathrm{UO}_{2} \mathrm{~F}_{2}$ at the rotary kiln entry to $\mathrm{U}_{3} \mathrm{O}_{8}$ or $\mathrm{UO}_{2}$ at the exit, depending on the type of conversion kiln considered (see densities in Table 2). The bulk density or the angle of repose considered at a given axial position is the mean -weighted by the composition of the solid phase at this axial position- of the bulk densities or the angles of repose of the different types of powders (given in Table 2). The composition of the solid phase is obtained by calculations involving a mass transfer model (Debacq, 2001) that will be detailed in another paper. The hydrodynamic model and the mass transfer model are of course coupled, and are also coupled to the thermal model. Since it is not possible to solve these coupled models in parallel, an iterative calculation is required to achieve convergence on the conversion, local hold-up and temperature profiles (Debacq, 2001) that will be the object of a third paper.

To summarize, the constant parameters in equations (1) and (2) are the kiln inclination angle $\alpha$, the rotational speed $\omega$ and the inside kiln radius $\mathrm{R}$. The dynamic angle of repose $\theta$ and the volumetric flow rate $Q_{v}$ are calculated from the composition of the solid phase at each axial position. The bed depth profile $h$ versus $x$ is obtained from equation (1) with the boundary condition $h=h_{p}$ at the kiln exit. Finally the local kiln hold-up $\mathrm{Z}$ is calculated from equation (2) and the $\mathrm{h}(\mathrm{x})$ value at each axial position. 


\subsection{Transverse solid distribution}

As mentioned in the introduction, some studies reported in the literature make it possible to calculate the amount of powder falling through the gas and sometimes the dense phase hold-up. Several calculations (Matchett and Baker, 1987, 1988; Sherritt et al., 1993; Blumberg and Schlünder, 1996) are based on two hypotheses which are not verified in the present case: first, the absence of solid in the bulk (the calculation of the length of particle fall from a lifter is then simplified) and second, the calculation of the fall velocity as that of a single particle in free fall at a low Reynolds number; it is then necessary to be able to define the diameter of the particle. The particles considered in the present study, however, are not only particularly cohesive (Carr's index is more than 0.4 and the Hausner ratio is more than 1.4 , as can be seen in Table 2) but are also formed of more or less coherent aggregates of small-sized elementary particles and therefore have a broad granular distribution (see Table 2); this means that it is not possible to define an appropriate particle size for the terminal fall velocity as is necessary for classical evaluation methods. Sherritt et al. (1994) proposed an iterative procedure to calculate the change in bulk depth along the rotary kiln; however their method to calculate the hold-up in a lifter can only be applied to freeflowing granular materials and is thus not applicable to our case. Ajayi and Sheehan (2012a, 2012b) recently published experimental studies using image analysis techniques to quantify the airborne solids, again for free-flowing and coarse particles, while in this work fine-grained cohesive powders are considered.

In order to find the transverse solid distribution (the 'snapshot' mentioned in the introduction and shown on Fig. 0 / Graphical abstract), i.e. not only the amount of powder falling through the gas but also the total flighted powder and the amount of powder in the bulk (which varies along the conversion kiln), the method of calculation described in the following sections is proposed.

\subsubsection{Powder fraction falling through the gas}

To calculate the powder fraction falling through the gas, it is necessary to determine the length of fall of the powder (see the Appendix) and therefore to know the quantity of solid present in the bulk. This quantity will be deduced (see section 2.2.3) from the local kiln hold-up calculated using the SaemanKramers-Afacan model (as explained in section 2.1), the flighted powder fraction (calculated by the procedure described in section 2.2.2) and the powder fraction falling through the gas which is sought to be determined here. An iterative calculation is therefore needed until convergence on the value of the three fractions is achieved; convergence between the local hold-up profile (values of $\mathrm{Z}$ for each axial position) and conversion of the powder is ensured in the global model.

The powder fraction $\eta_{\mathrm{G}}$ falling through the gas is determined by a calculation procedure involving the powder fraction $\mathrm{q}$ falling from one lifter between time $\mathrm{t}$ and $\mathrm{t}+\delta \mathrm{t}$. For a given rotation speed $\omega$, $\mathrm{q}$ can be calculated using equation (3) which also takes into account the slope $\chi$ of the lifter discharge law $\xi=\chi \cdot\left(\gamma_{\mathrm{F}}-\gamma\right)$ determined in a previous study (see notations on Fig. 1).

$$
\mathrm{q}=\chi \cdot 2 \pi \omega \cdot \delta \mathrm{t}
$$

The parameters of the discharge law were measured in the operating conditions of uranium conversion kilns, i.e. at high temperatures (Debacq et al., 2013); in addition to the slope $\chi$, these measurements provided the values of the following characteristic angles (the notations used are indicated on Fig. 1):

- $\gamma_{D}$ : lifter position for which the powder it contains is no longer in contact with the powder remaining in the bulk;

- $\gamma_{\mathrm{I}}$ : start of 'effective' discharge, with reference to the mass transfer between solid and gaseous reagents;

- $\gamma_{\mathrm{F}}$ : lifter position at which the last powder particle falls.

For the calculations described in the present paper, the slope and characteristic angles considered at a given axial position are the means -weighted by the composition of the solid phase at this axial positionof the characteristic slopes and angles of the different types of powders (see values in section 3). The relevant angles for the calculation of $\eta_{\mathrm{G}}$ are $\gamma_{\mathrm{I}}$ and $\gamma_{\mathrm{F}}$.

The powder fraction $q$ falls during a time $t_{\text {fall }}$ which is equal to the length of fall $h_{\text {fall }}$ (see notations on Fig. 1 and the demonstration in the Appendix) divided by the fall velocity $\mathrm{v}_{\text {fall }}$ and by the cosine of the kiln inclination angle $\alpha$, according to equation (4). It was observed that in a cross-section of the rotary kiln, 
the powder falls almost vertically from the lifters at the rotational speeds used, as shown on Fig. 2; it is therefore unnecessary to take any deviation of the particle path in the transverse plane into account. However, the kiln inclination itself can be taken into account via cosine $\alpha$ in equation (4). The fall velocity is determined experimentally at high temperature (see section 3). After falling, the powder fraction $q$ therefore remains present in the gas phase between time $t$ and $t+t_{\text {fall }}$.

$$
\begin{aligned}
\mathrm{t}_{\text {fall }} & \frac{\left(\mathrm{R}-\mathrm{h}_{\mathrm{o}}\right) \cdot \sin \gamma+\mathrm{h}_{\mathrm{p}} \cdot \cos \gamma+\mathrm{R} \cdot \cos \left(\frac{\Gamma}{2}+\theta\right)}{\cos \alpha \cdot \mathrm{v}_{\text {fall }}} \\
& -\frac{\tan \theta}{\cos \alpha \cdot \mathrm{v}_{\text {fall }}} \cdot\left[\left(\mathrm{R}-\mathrm{h}_{\mathrm{o}}-\mathrm{h}_{\mathrm{p}} \cdot \tan \gamma\right) \cdot \cos \gamma-\mathrm{R} \cdot \sin \left(\frac{\Gamma}{2}+\theta\right)\right]
\end{aligned}
$$

The angle $\Gamma$ in equation (4) is related to the fraction $\eta_{\text {в }}$ of powder remaining in the bulk by equation (5). As this relation is implicit in $\Gamma$, and since an iteration loop would have further increased the already large number of iterative calculations in the global rotary kiln model (Debacq, 2001), a numerical approximation is used to optimize the calculation time: equation (6) for $\eta_{B}<0.05$ and equation (7) for $\eta_{\mathrm{B}} \geq 0.05$. The agreement between equation (5) and the approximations (6) and (7) is shown on Fig. 3.

$$
\begin{aligned}
& \eta_{\mathrm{B}}=\frac{\Gamma-\sin \Gamma}{2 \pi} \\
& \Gamma=5.4870 \times \ln \left(\eta_{\mathrm{B}}{ }^{0.4457}+1\right) \\
& \Gamma=12.5965 \times \log \left(\eta_{\mathrm{B}} 0.6518+1.1219\right)
\end{aligned}
$$

The value of $\Gamma$ also makes it possible to recalculate the detachment angle $\gamma_{D}$ corresponding to the quantity of solid in the bulk, using equation (8).

$$
\gamma_{D}= \begin{cases}\frac{\pi}{2}-\theta-\frac{\Gamma}{2}, & \text { for } \theta+\frac{\Gamma}{2} \leq \frac{\pi}{2} \\ \theta+\frac{\Gamma}{2}-\frac{\pi}{2}, & \text { for } \theta+\frac{\Gamma}{2} \geq \frac{\pi}{2}\end{cases}
$$

The powder fraction $\eta_{G}$ falling through the gas at a given axial position is calculated by the following procedure:

1. Depending on the kiln rotational speed, the position of each lifter is calculated at each instant (a time-step $\delta \mathrm{t}=0.01 \mathrm{~s}$, i.e. $0.12^{\circ}$ at $2 \mathrm{rpm}$ for example was chosen) during $(1+1 / \mathrm{n})$ revolutions (where $\mathrm{n}$ is the number of lifters inside the kiln); lifter number 1 is conventionally positioned at an angle $\gamma=0$ at time $\mathrm{t}=0$; the other lifters have an incremented number counterclockwise.

2. At a given axial position (and therefore for a local kiln hold-up and characteristics of the discharge law $\left(\chi, \gamma_{I}\right.$ and $\left.\gamma_{F}\right)$ given by the composition of the solid phase), and for each instant, the lifters that are in 'effective' discharge are selected (i.e. angular position between $\gamma_{\mathrm{I}}$ and $\gamma_{\mathrm{F}}$ ); this number is usually 2 or 3 for kiln \#1 for example (this is the number of arrows in each box on Fig. 4). The quantity of powder $q$ which falls from each lifter during the time-step $\delta t$ is then calculated according to equation (3), as well as the fall time needed for each 'clump' of powder to fall from each lifter in 'effective' discharge, using equations (4) and (6) or (7).

3. From this, the number of time-steps during which each 'clump' of powder is airborne is deduced. The total powder fraction falling through the gas is then incremented at each subsequent timestep, as shown on Fig. 4. For example, for lifter 1 in the first time-step (beige arrow on colored version of Fig. 4 or gray arrow on black and white version of Fig. 4, on the left of Fig. 4), if it takes five time-steps for the powder fraction falling from lifter number 1 to reach the bulk in the bottom of the kiln, the corresponding quantity of powder (small beige or gray rectangles) is airborne for five time-steps; if it takes three time-steps for the powder fraction falling from lifter number 2 to reach the bulk in the bottom of the kiln (brown or black arrow on Fig. 4), the corresponding quantity of powder (small brown or black rectangles) is airborne for three timesteps, and so on for each lifter at each time-step. 
4. Once the steady state regime has been reached (usually in fact in much less than one revolution), the instantaneous total powder fraction falling through the gas oscillates around an average value, as shown on Fig. 5, with a frequency corresponding to the time interval between the passage of two successive lifters at a given angular position $\gamma$ (i.e. $1 / \mathrm{n}$ revolution). That is why the powder fraction $\eta_{\mathrm{G}}$ falling through the gas is calculated by averaging over the instants between 1 and $(1+1 / n)$ revolutions (see Fig. 4$)$.

5. Steps 2 to 4 of this procedure are repeated for different axial positions along the cylinder.

Note that the length of the discretization segments of the cylinder always corresponds to a time interval at least equal to, and generally greater than, the time required for the kiln to perform $1+1 / \mathrm{n}$ revolutions (Debacq, 2001).

To summarize, the constant parameters in equations (3) to (8) are the kiln inclination angle $\alpha$, the rotational speed $\omega$, the inside kiln radius $R$, the dimensions of the lifters $h_{o}$ and $h_{p}$ and the fall velocity $\mathrm{V}_{\text {fall. }}$ The dynamic angle of repose $\theta$, the slope of discharge law $\chi$ and the characteristic angles $\gamma_{\mathrm{I}}$ and $\gamma_{\mathrm{F}}$ are calculated from the composition of the solid phase at each axial position. This allows to calculate $\mathrm{q}$ from equation (3) and to determine the lifters that are in discharge in step 2 of the previous procedure. The duration of the fall can then be calculated from equation (4), in which the filling angle $\Gamma$ is obtained from approximation (6) or (7) depending on the value of $\eta_{\mathrm{B}}$ in the previous iteration. The value of the filling angle $\Gamma$ also allows to calculate $\gamma_{D}$ from equation (8); this value is necessary for the determination of $\eta_{\mathrm{F}}$. Step 3 of the procedure can then be carried out (Fig. 4). Once the time interval has been investigated in full, it is possible to calculate $\eta_{\mathrm{G}}$ for the considered axial position (Fig. 5) according to step 4 of the procedure. As mentioned in section 2.1, since the determinations of $\eta_{\mathrm{G}}, \eta_{\mathrm{F}}$ and $\eta_{\mathrm{B}}$ are not independent, an iterative calculation is necessary to achieve convergence between these three values: an estimated value of $\eta_{B}$ is needed to determine $\eta_{G}$; since the calculation of $\eta_{G}$ uses the filling angle $\Gamma$, which is itself a function of $\eta_{\mathrm{B}}$ (see equation (5)), this is what is used to test convergence.

\subsubsection{Flighted powder fraction}

The total flighted powder fraction $\eta_{\mathrm{F}}$ is determined using a calculation procedure that involves only the lifter discharge law $\xi=\chi \cdot\left(\gamma_{\mathrm{F}}-\gamma\right)$ determined in a previous work (Debacq et al., 2013) (see the notations on Fig. 1). The appropriate angles for the calculation of $\eta_{F}$ are $\gamma_{D}$ and $\gamma_{F}$.

The procedure is as follows:

1. Depending on the kiln rotational speed, the position of each lifter is calculated at each time-step (a time-step of $0.01 \mathrm{~s}$ was also chosen here) during $1 / \mathrm{n}$ revolutions (where $\mathrm{n}$ is again the number of lifters); lifter number 1 is again conventionally positioned at an angle $\gamma=0$ at time $t=0$.

2. At a given axial position (and therefore for a local kiln hold-up and characteristics of the discharge law $\left(\chi, \gamma_{D}\right.$ and $\left.\gamma_{F}\right)$ given by the composition of the solid phase), and for each instant, the powder fraction in each lifter is calculated using the discharge law.

3. In this procedure, no steady state settling is needed; the total flighted powder fraction oscillates as a function of angular position around the average value $\eta_{\mathrm{F}}$, as shown on Fig. 6.

4. Knowing the average fraction $\eta_{\mathrm{F}}$, the 'typical' lifter angular position that it corresponds to is determined, by taking the values obtained at all angular positions. The average whole number of lifters that are detached $\left(\gamma>\gamma_{\mathrm{D}}\right)$ and that contain solid $\left(\gamma<\gamma_{\mathrm{F}}\right)$ in this typical position is also determined. The angular position and number are useful for the mass transfer and thermal models (Debacq, 2001).

5. Steps 2 to 4 of this procedure are repeated for different axial positions along the conversion kiln.

\subsubsection{Powder fraction in the bulk}

The fraction $\eta_{\mathrm{B}}$ of solid in the bulk is obtained for each axial position by a simple subtraction (9).

$$
\eta_{\mathrm{B}}(\mathrm{x})=\mathrm{Z}(\mathrm{x})-\eta_{\mathrm{G}}(\mathrm{x})-\eta_{\mathrm{F}}(\mathrm{x})
$$




\section{EXPERIMENTAL MEASUREMENTS}

The dimensions and nominal operating conditions of industrial kilns studied here are given in Table 1: in the type of rotary kiln used for depleted uranium conversion and named "kiln \#1", uranyl difluoride $\left(\mathrm{UO}_{2} \mathrm{~F}_{2}\right)$ is converted into uranium sesquioxide $\left(\mathrm{U}_{3} \mathrm{O}_{8}\right)$; in the type of conversion kiln used for enriched uranium and named "kiln \#2", uranyl difluoride $\left(\mathrm{UO}_{2} \mathrm{~F}_{2}\right)$ is converted into uranium dioxide $\left(\mathrm{UO}_{2}\right)\left(\mathrm{U}_{3} \mathrm{O}_{8}\right.$ is an intermediate during the conversion from $\mathrm{UO}_{2} \mathrm{~F}_{2}$ to $\mathrm{UO}_{2}$ ). These two types of kiln differ in dimensions and nominal operating conditions, but the same model is used to describe them.

The properties of the different powders are given in Table 2. It can be seen that the oxides are clearly cohesive (Carr's index is more than 0.4 and the Hausner ratio is more than 1.4); $\mathrm{UO}_{2} \mathrm{~F}_{2}$ is on the borderline of highly cohesive powders.

The experimental determination of the discharge law was described elsewhere (Debacq et al., 2013). The values found are:

- slope of discharge law: $\chi=0.00012^{\circ-1}$ for $\mathrm{UO}_{2} \mathrm{~F}_{2}$ and $0.00035^{\circ-1}$ for oxides;

- detachment angle: $\gamma_{\mathrm{D}}=-18^{\circ}$ for all powders (rough value measured for mean hold-up; $\gamma_{\mathrm{D}}$ can be calculated from the filling angle through equation (8));

- angle at the start of effective discharge ('effective' with reference to mass transfer between solid and gaseous reagents): $\gamma_{\mathrm{I}}=-2^{\circ}$ for $\mathrm{UO}_{2} \mathrm{~F}_{2}$ and $80^{\circ}$ for oxides at high temperatures;

- angle at the end of discharge: $\gamma_{\mathrm{F}}=131^{\circ}$ for all powders.

As discussed previously (Debacq et al., 2013), at room temperature the different powders behave in the same way (same values of slope and angles). At high temperatures (those of the process), however, while the behavior of $\mathrm{UO}_{2} \mathrm{~F}_{2}$ remains similar to that under cold conditions, oxides have a very different behavior and powder discharge from the lifters is much like a sandcastle being unmolded from a bucket on a beach. The values of $\gamma_{\mathrm{I}}$ and $\gamma_{\mathrm{F}}$ used in the calculations presented in the present paper are those given above; the value of $\gamma_{D}$ is calculated at each axial position using equation (8).

Fig. 2 is obtained by overlaying on the same image the powder curtains falling from the lifter tips from various angular positions. They were obtained from the images used to determine the discharge law (Debacq et al., 2013). In a cross-section of the drum, because of the rotational speed, the particles do not fall exactly vertically. Since the vertical deviation is weak, however, it will be neglected here. Several studies also report quasi-vertical particle paths (Prutton et al., 1942; Kelly and O'Donnell, 1968; Britton et al., 2006; Ahmadian et al., 2011; Ajayi and Sheehan, 2012a, 2012b; Sunkara et al., 2013a, 2013b).

As mentioned in section 2.2, the classical methods used to calculate the fall velocity of the particle curtains cannot be applied to the powders considered in the present study, as they are particularly cohesive and have a broad granular distribution (Table 2). It therefore seemed preferable to determine the velocity experimentally.

The setup designed to determine the discharge laws at high temperature (Debacq et al., 2013) was reused for the present measurements in stagnant air. A graph plate was placed vertically behind the right-angled flight. The flight was rotated manually at a speed close to that encountered in industrial kilns. The recorded films were used to measure the velocity of the front ahead and behind the powder, which fell in 'clumps' through the gas, as described elsewhere (Debacq et al., 2013). The fall velocity measured -in temperature conditions around $700-800^{\circ} \mathrm{C}$ - was $\mathbf{1} \mathbf{~ m ~ s}^{-1}$, with a range over the seven tests and five measurements per test, between 0.8 and $1.2 \mathrm{~m} \mathrm{~s}^{-1}$. There was no significant difference between the velocity of the upstream and downstream powder fronts. This value is similar to that obtained by Kelly and O'Donnell (1968).

\section{RESULTS AND DISCUSSION}

\subsection{Flighted powder fraction}

If the time-step selected for the calculation procedure is sufficiently small, the rotational speed has no influence on $\eta_{F}$. Fig. 7 a shows the variations in the $\eta_{F}$ fraction (in green on the colored version of Fig. $7 \mathrm{a}$ / in black on the black and white version of Fig. 7a) as a function of the local kiln hold-up: at low hold- 
up, $\eta_{\mathrm{F}}$ increases with $\mathrm{Z}$ up to a maximum value $\left(\eta_{\mathrm{F}}=0.0284\right.$ for $\mathrm{Z}=3.5 \%$ in the conditions of Fig. $\left.7 \mathrm{a}\right)$; it then decreases slightly until a minimum $\left(\eta_{\mathrm{F}}=0.0239\right.$ around $\mathrm{Z}=13.5 \%$ in the conditions of Fig. $\left.7 \mathrm{a}\right)$, when the solid begins to collect in the bulk and $\gamma_{\mathrm{D}}$ increases; beyond this value, $\eta_{\mathrm{F}}$ increases again since the lifters can be almost completely filled at small angular positions, as observed in the drums (Debacq et al., 2013). The first part of this curve is comparable to the results obtained by Ajayi and Sheehan (2012a) who investigated only relatively weak hold-up.

Because the powders used are highly cohesive, the flights can be heavily overloaded. As a result, saturation for $\eta_{F}$ is not yet achieved; $\eta_{F}$ continues therefore to increase slowly, even for values of $Z$ up to $50 \%$.

\subsection{Powder fraction falling through the gas}

In the operating conditions of industrial kilns, the fraction $\eta_{\mathrm{G}}$ is always very small. As q is proportional to the rotational speed, $\eta_{\mathrm{G}}$ also varies proportionally to $\omega$, as shown on Fig. 7b. Fig. 7a gives an example of the variations in the fraction $\eta_{\mathrm{G}}$ (in red/grey) as a function of the local kiln hold-up: at low hold-up, $\eta_{\mathrm{G}}$ increases with $\mathrm{Z}$ up to a maximum value identical to that for $\eta_{F}(3.5 \%$ in the conditions of Fig. $7 \mathrm{a})$; beyond this value, $\eta_{\mathrm{G}}$ decreases slightly since the length of fall decreases when the bed depth increases,

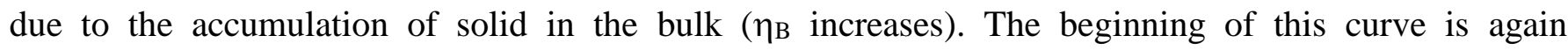
comparable to the results obtained by Ajayi and Sheehan (2012a).

\subsection{Axial profile of local kiln hold-up and transverse solid distribution}

Fig. 8 shows the axial profile of the local kiln hold-up for kiln \#1 under nominal operating conditions (see Table 1) and the average solid distribution at each axial position; molar flow rates of the reactant $\left(\mathrm{UO}_{2} \mathrm{~F}_{2}\right)$ and reaction product $\left(\mathrm{U}_{3} \mathrm{O}_{8}\right)$ are also plotted in Fig. 8. The local kiln hold-up is very high in the entry zone; it decreases by a factor of five between the entry and exit of the conversion kiln, due to the volume contraction between $\mathrm{UO}_{2} \mathrm{~F}_{2}$ at the entry and $\mathrm{U}_{3} \mathrm{O}_{8}$ at the exit (see bulk densities in Table 2). The powder fraction falling through the gas varies only slightly along the cylinder in comparison with the other fractions; it is approximately $0.3 \%$. The total flighted powder fraction increases slightly from the rotary kiln entry to the 6 meter mark, then remains practically constant at around 4\%; this corresponds to the gradual decrease in the fraction in the bulk $\eta_{\text {B }}$ up to the 6 meter mark: as the detachment angle $\gamma_{D}$ decreases, the lifters have more space outside the bulk, so the flighted powder fraction $\eta_{F}$ increases. Lastly, solid remains in the bulk almost up to the exit end of the conversion kiln.

Fig. 9 shows the axial profile of local kiln hold-up and the average solid distribution along kiln \#2 under nominal operating conditions (see Table 1); molar flow rates of the reactant $\left(\mathrm{UO}_{2} \mathrm{~F}_{2}\right)$, of the intermediate $\left(\mathrm{U}_{3} \mathrm{O}_{8}\right)$ and of the reaction product $\left(\mathrm{UO}_{2}\right)$ are also plotted in Fig. 9. Between the entry and exit of the conversion kiln, the local kiln hold-up decreases by a factor of three, again due to the volume contraction between $\mathrm{UO}_{2} \mathrm{~F}_{2}$ at the entry and $\mathrm{UO}_{2}$ at the exit (see bulk densities in Table 2). This decrease takes place mainly in the first half of the kiln, i.e. in the zone where $\mathrm{UO}_{2} \mathrm{~F}_{2}$ is consumed (compare its flow rate with hold-up in Fig. 9); as the bulk density difference between $\mathrm{U}_{3} \mathrm{O}_{8}$ and $\mathrm{UO}_{2}$ is smaller, the local kiln hold-up thus decreases slowly. The powder fraction falling through the gas is about $0.4 \%$ along the whole length of the kiln. The total flighted powder fraction is about 3.3\%; it increases slightly from the entry of the conversion kiln to the 2.3 meter mark, simultaneously with the decrease of $Z$; then $\eta_{F}$ decreases slightly until the kiln exit, parallel to the decrease of Z. Lastly, no solid remains outside the lifters -that is in the bulk- between the 2.3 meter mark and the exit, because $\mathrm{Z}$ is too low in this area: the powder falling from the lifters no longer supplies the bulk, but fills the flights directly. Furthermore the lifters cannot be completely filled and are less and less loaded as $\mathrm{Z}$ decreases, thus $\eta_{\mathrm{F}}$ continues to decline until the exit of the kiln.

The main difference between the two types of kiln is their hold-up: the flow rate in kiln \#2 is about ten times lower than in kiln \#1, while kiln \#2 is only about half the size of kiln \#1 (see dimensions and nominal operating conditions of the kilns in Table 1). This has an important impact on the axial profile of the local kiln hold-up (in particular on the hold-up value at the conversion kiln entry) and on the relative 
distribution of powder falling through the gas, flighted powder and bulk powder, as can be seen by comparing Figs. 8 and 9.

Industrial rotary kilns are not standalone devices: they are preceded by a hydrolysis reactor which feeds directly into the kiln through an endless screw, which prevents backflow by continuously pushing the powder. From the experience of the operators of kilns \#1, problems with the screw periodically occur that are consistent with a high filling degree at this location; however the operators of kilns \#2 never faced this type of problem, which is consistent with the substantially lower filling degree calculated at the entrance of this second type of kilns.

Figs. 8 and 9 show that the volume contraction effect resulting from the reactions that take place in uranyl difluoride conversion kilns is very significant. In order to validate the model presented here, it would be necessary to measure the axial profiles of local kiln hold-up and the transverse solid distribution under reactive conditions, i.e. in the presence of uranium and hydrofluoric acid, at a temperature around $800^{\circ} \mathrm{C}$. The few measurements reported in the literature (Lebas et al., 1995; Chatterjee et al., 1983; Sai et al., 1990; Spurling et al., 2001) were not only conducted on unflighted rotary kilns but more importantly, were completely out of the question here for reasons concerning the safety of the workers and of the installations. We had originally intended to exploit the weak radioactivity of uranium in order to measure the overall axial distribution of the powder along the kiln. Unfortunately this proved to be impossible due to the congested surroundings of the industrial kiln (lagging, various systems of measurement and monitoring, etc.): the gamma-ray signal was not usable.

\section{CONCLUSIONS}

In this study, a method to calculate the axial and transverse solid distribution of the powder in flighted rotary kilns is proposed (in the form of a series of 'snapshots', as shown on Fig. 0 / Graphical abstract), i.e. not only the quantity of powder falling through the gas, but also the total quantity of flighted powder, as well as the quantity remaining in the bulk. This method does not require defining a particle size, which would be meaningless in the case of fine-grained cohesive powders. The method is based on geometrical calculations and on experimental measurements conducted in the temperature conditions of the industrial plant being modeled.

The very substantial volume contraction in the modeled conversion kilns leads to a significant variation in the local hold-up between the entry (uranyl difluoride) and the exit (uranium dioxides) of the kilns. Whatever the type of conversion kiln considered, the powder fraction falling through the gas varies only slightly along the length of the kiln and is below $0.5 \%$. The total flighted powder fraction varies between $2 \%$ and $4 \%$ along the kiln. The powder fraction remaining in the bulk varies considerably, up to $41 \%$ in kiln \#1 and from 0 to $11 \%$ in kiln \#2 for the nominal operating conditions of these conversion kilns.

It should be emphasized that the results obtained here are specifically related to the highly cohesive character of the powders studied and to the fact that the conversion leads to a very strong variation in their properties (bulk density in particular).

The hydrodynamic model described in the present paper forms the basis for the global model of rotary kilns used for the conversion of uranium (Debacq, 2001). With the 'snapshots' that have been determined thanks to this hydrodynamic model, it is possible to calculate all the thermal exchange surfaces. The calculation of the flighted powder fraction, the powder fraction falling through the gas, and the fraction remaining in the bulk, enable the mass transfers to be assessed using the mass transfer model (Debacq, 2001).

\section{Acknowledgements}

This work was supported by a grant from $\mathrm{FBFC}^{2}$ Romans (France) and Cogema ${ }^{3}$ Pierrelatte (France). We gratefully acknowledge André FEUGIER and Didier HARTMANN for their kind help in this work.

\footnotetext{
${ }^{2}$ Franco-Belge de Fabrication de Combustible

${ }^{3}$ Compagnie Générale des Matières Nucléaires
} 


\section{NOMENCLATURE}

\section{Latin characters}

$\mathrm{d}_{\mathrm{p}}[\mathrm{m}] \quad$ particle size

$\mathrm{h}[\mathrm{m}] \quad$ bed depth at a given axial position

$\mathrm{h}_{\text {fall }}[\mathrm{m}] \quad$ length of fall from a lifter

$\mathrm{h}_{\mathrm{o}}[\mathrm{m}] \quad$ lifter dimension normal to the kiln wall

$\mathrm{h}_{\mathrm{p}}[\mathrm{m}] \quad$ lifter dimension parallel to the kiln wall

$\mathrm{n}$ [-] number of flights inside kiln

$\mathrm{q}[-] \quad$ powder fraction falling from one lifter between time $t$ and $t+\delta t$

$\mathrm{Q}_{\mathrm{v}}\left[\mathrm{m}^{3} \mathrm{~s}^{-1}\right] \quad$ volumetric flow rate

$\mathrm{R}[\mathrm{m}] \quad$ inside kiln radius

$t_{\text {fall }}[\mathrm{s}] \quad$ time of fall from a lifter

$\mathrm{V}_{\text {fall }}\left[\mathrm{m} \mathrm{s}^{-1}\right] \quad$ fall velocity of the powder

$\mathrm{x}[\mathrm{m}] \quad$ axial position in the kiln (distance from the solid feed)

$\mathrm{Z}[-] \quad$ local kiln hold-up (at a given axial position)

\section{Greek symbols}

$\alpha\left[^{\circ}\right] \quad$ inclination of the kiln

$\chi\left[^{\left.{ }^{0-1}\right]} \quad\right.$ slope of the lifter discharge law

$\delta\left[^{\circ}\right] \quad$ avalanche angle (instantaneous angle of repose made by particles in a flight with respect to horizontal)

$\gamma\left[{ }^{\circ}\right] \quad$ angular position of the lifter (with respect to the horizontal)

$\gamma_{\mathrm{D}}\left[{ }^{\circ}\right] \quad$ detachment angle

$\gamma_{\mathrm{F}}\left[^{\circ}\right] \quad$ angle at the end of discharge

$\gamma_{\mathrm{I}}\left[{ }^{\circ}\right] \quad$ angle at the start of effective discharge

$\Gamma[\mathrm{rad}] \quad$ filling angle (central angle extended by solid bed) at a given axial position

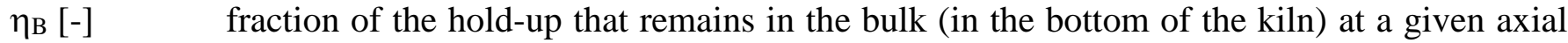
position

$\eta_{\mathrm{F}}[-] \quad$ fraction of the hold-up that is flighted at a given axial position

$\eta_{\mathrm{F}}[-] \quad$ total flighted powder fraction at a given angular and axial position

$\eta_{\mathrm{G}}[-] \quad$ fraction of the hold-up that is in gaseous phase (airborne) at a given axial position

$\wedge$

$\eta_{\mathrm{G}}[-] \quad$ instantaneous total powder fraction falling through the gas at a given axial position

$\theta\left[{ }^{\circ}\right] \quad$ dynamic angle of repose

$\omega[\mathrm{rpm}] \quad$ rotational speed of the kiln

$\xi[-] \quad$ volume fraction occupied by the powder contained in one lifter (with respect to the total volume of the drum); i.e. lifter hold-up 


\section{REFERENCES}

Afacan, A., Masliyah, J.H., 1990. Solid hold-up in rotary drums. Powder Technol. 61(2), 179-184. doi:10.1016/0032-5910(90)80153-P

Ahmadian, H., Hassanpour, A., Ghadiri, M., 2011. Analysis of granule breakage in a rotary mixing drum: Experimental study and distinct element analysis. Powder Technol., 210 (2), 175-180. doi:10.1016/j.powtec.2011.03.013

Ajayi, O.O., Sheehan, M.E., 2012a. Application of image analysis to determine design loading in flighted rotary dryers. Powder Technol. 223, 123-130. doi:10.1016/j.powtec.2011.05.013

Ajayi, O.O., Sheehan, M.E., 2012b. Design loading of free flowing and cohesive solids in flighted rotary dryers. Chem. Eng. Sci. 73, 400-411. doi:10.1016/j.ces.2012.01.033

Blumberg, W., Schlünder, E.U., 1996. Transverse bed motion and convective mass transfer in rotary cylinders. Part 2. With lifters. Chem. Eng. Process. 35(6), 405-411. doi:10.1016/S0255-2701(96)04151-7

Boateng, A.A., 2008. Rotary Kilns, Ed. Butterworth-Heinemann, Oxford.

Britton, P.F., Sheehan, M.E., Schneider, P.A., 2006. A physical description of solids transport in flighted rotary dryers. Powder Technol. 165(3), 153-160. doi:10.1016/j.powtec.2006.04.006

Chatterjee, A., Sathe, A.V., Srivastava, M.P., Mukhopadhyay, P.K., 1983. Flow of Materials in Rotary Kilns Used for Sponge Iron Manufacture: Part I. Effect of Some Operational Variables. Metall. Trans. B 14(3), 375-381. doi:10.1007/BF02654356

Debacq, M., 2001. Étude et modélisation des fours tournants de défluoration et réduction du difluorure d'uranyle, Ph.D. Thesis, Institut National Polytechnique de Lorraine, Nancy, France.

Debacq, M., Vitu, S., Ablitzer, D., Houzelot, J.L., Patisson, F., 2013. Transverse motion of cohesive powders in flighted rotary kilns: experimental study of unloading at ambient and high temperatures. accepted for publication in Powder Technol. on 04/04/2013. doi:10.1016/j.powtec.2013.04.007

Descoins, N., Dirion, J.L., Howes, T., 2005. Solid transport in a pyrolysis pilot-scale rotary kiln: preliminary results-stationary and dynamic results. Chem. Eng. Process. 44(2), 315-321. doi:10.1016/j.cep.2004.02.025

Fernandes, N. J., Ataíde, C. H., Barrozo, M. A. S., 2009. Modeling and experimental study of hydrodynamic and drying characteristics of an industrial rotary dryer. Braz. J. Chem. Eng. 26(2), 331 341. doi:10.1590/S0104-66322009000200010

Friedman, S. J., Marshall, W. R. Jr., 1949. Studies in rotary drying, part I. Holdup and dusting. Chem. Eng. Prog. 45(8), 482-493.

Henein, H., Brimacombe, J.K., Watkinson, A.P., 1983. Experimental studies of transverse bed motion in rotary kilns. Metall. Trans. B 14B(2), 191-205. doi:10.1007/BF02661016

Kelly, J.J., O'Donnell, J.P., 1968. Dynamics of granular material in rotary dryers and coolers. Inst. Chem. Eng. 29, 34-44.

Kramers, H., Croockewit, P., 1952. The passage of granular solids through inclined rotary kilns. Chem. Eng. Sci. 1(6), 259-265. doi:10.1016/0009-2509(52)87019-8

Lebas, E., Hanrot, F., Ablitzer, D., Houzelot, J.L., 1995. Experimental study of residence time, particle movement and bed depth profile in rotary kilns. Can. J. Chem. Eng. 73(2), 173-180. doi:10.1002/cjce.5450730202

Marias, F., Roustan, H., Pichat, A., 2005. Modelling of a rotary kiln for the pyrolysis of aluminium waste. Chem. Eng. Sci. 60, 4609-4622. doi:10.1016/j.ces.2005.03.025

Matchett, A.J., Baker, C.G.J., 1987. Particle residence times in cascading rotary dryers, Part 1 Derivation of the two-stream model. J. Sep. Process Technol. 8, 11-17.

Matchett, A.J., Baker, C.G.J., 1988. Particle residence times in cascading rotary dryers, Part 2 Application of the two-stream model to experimental and industrial data. J. Sep. Process Technol. 9, 5-13. Meade, R. K., 1914. The Development of the Rotary Kiln and Its Application to Various Chemical and Metallurgical Processes. Ind. Eng. Chem. 6(9), 754-760.

Mellmann, J., 2001. The transverse motion of solids in rotating cylinders-forms of motion and transition behaviour. Powder Technol. 118(3), 251-270. doi:10.1016/S0032-5910(00)00402-2

Mujumdar, K.S., Ranade, V.V., 2006. Simulation of Rotary Cement Kilns Using a One-Dimensional Model. Chem. Eng. Res. Des. 84(3), 165-177. doi: 10.1205/cherd.04193 
Prutton, C.F., Miller, C.O., Schuette, W.H., 1942. Factors influencing the performance of rotary dryers. AIChE Trans. 38, 123-141.

Saeman, W. C., 1951. Passage of solids through rotary kilns: factors affecting time of passage. Chem. Eng. Prog. 47(10), 508-514.

Sai, P.S.T., Sankaran, K., Philip, Z.G., Suresh, V., Damodaran, A.D., Surender, G.D., 1990. Residence time distribution and material flow studies in a rotary kiln. Metall. Trans. B 21(6), 1005-1011. doi:10.1007/BF02670271

Schofield, F.R., Glikin, P.G., 1962. Rotary Driers and Coolers for Granular Fertilizers. Trans. Inst. Chem. Eng. 40, 183-190.

Shahhosseini, S., Cameron, I. T., Wang, F.Y., 2000. A simple dynamic model for solid transport in rotary dryers. Drying Technol., 18(4\&5), 867-886. doi:10.1080/07373930008917742

Sherritt, R.G., Caple, R., Behie, L.A., Mehrotra, A.K., 1993. The Movement of Solids Through Flighted Rotating Drums. Part I: Model Formulation. Can. J. Chem. Eng. 71(3), 337-346. doi:10.1002/cjce.5450710302

Sherritt, R.G., Caple, R., Behie, L.A., Mehrotra, A.K., 1994. The Movement of Solids Through Flighted Rotating Drums. Part II: Solids-gas interaction and model validation. Can. J. Chem. Eng. 72(2), 240-248. doi:10.1002/cjce.5450720210

Specht, E., Shi, Y.C., Woche, H., Knabbe, J., Sprinz, U., 2010. Experimental investigation of solid bed depth at the discharge end of rotary kilns. Powder Technol. 197, 17-24. doi:10.1016/j.powtec.2009.08.024

Spurling, R.J., Davidson, J.F., Scott, D.M., 2001. The transient response of granular flows in an inclined rotating cylinder. Chem. Eng. Res. Des. 79(A1), 51-61. doi:10.1205/026387601528525

Sunkara, K.R., Herz, F., Specht, E., Mellmann, J., Erpelding, R., 2013a. Modeling the discharge characteristics of rectangular flights in a flighted rotary drum, Powder Technol. 234, 107-116. doi:10.1016/j.powtec.2012.09.007

Sunkara, K.R., Herz, F., Specht, E., Mellmann, J., 2013b. Influence of flight design on the particle distribution of a flighted rotating drum. Chem. Eng. Sci. 90, 101-109. doi:10.1016/j.ces.2012.12.035

Thammavong, P., Debacq, M., Vitu, S., Dupoizat, M., 2011. Experimental apparatus for studying heat transfer in externally heated rotary kilns. Chem. Eng. Technol., 34(5), 707-717. doi:10.1002/ceat.201000391

Vàhl, L., Kingma, W.G., 1952. Transport of solids through horizontal rotary cylinders. Chem. Eng. Sci. 1(6), 253-258. doi:10.1016/0009-2509(52)87018-6

Van Puyvelde, D.R., 2009. Modelling the hold up of lifters in rotary dryers. Chem. Eng. Res. Des. 87, 226-232. doi:10.1016/j.cherd.2008.08.018

Wang, F.Y., Cameron, I.T., Litster, J.D., Rudolph, V., 1995. A fundamental study of particle transport through rotary dryers for flight design and system optimisation. Drying Technol. 13(5-7), 1261-1278. doi:10.1080/07373939508917021 
Considering the notations on Fig. A. 1:

$\mathrm{AC}=\frac{\mathrm{h}_{\mathrm{p}}}{\cos \gamma}, \mathrm{CD}=\mathrm{OC} \cdot \sin \gamma$ and $\mathrm{DE}=\mathrm{R} \cdot \sin \nu$,

with $\mathrm{OC}=\mathrm{R}-\mathrm{h}_{\mathrm{o}}-\mathrm{BC}=\mathrm{R}-\mathrm{h}_{\mathrm{o}}-\mathrm{h}_{\mathrm{p}} \cdot \tan \gamma$, and $\mathrm{OC} \cdot \cos \gamma=\mathrm{OD}=\mathrm{R} \cdot \cos \nu$,

The coordinates of the points in the reference frame $(\mathrm{O}, \mathrm{x}, \mathrm{y})$ are as follows:

$$
\begin{aligned}
& \mathrm{A}\left|\begin{array}{l}
\left(\mathrm{R}-\mathrm{h}_{\mathrm{O}}\right) \cdot \cos \gamma-\mathrm{h}_{\mathrm{p}} \cdot \sin \gamma \\
\left(\mathrm{R}-\mathrm{h}_{\mathrm{O}}\right) \cdot \sin \gamma+\mathrm{h}_{\mathrm{p}} \cdot \cos \gamma
\end{array} ; \mathrm{B}\right| \begin{array}{l}
\left(\mathrm{R}-\mathrm{h}_{\mathrm{o}}\right) \cdot \cos \gamma \\
\left(\mathrm{R}-\mathrm{h}_{\mathrm{o}}\right) \cdot \sin \gamma
\end{array} ; \mathrm{C} \mid \begin{array}{l}
\left(\mathrm{R}-\mathrm{h}_{\mathrm{o}}-\mathrm{h}_{\mathrm{p}} \cdot \tan \gamma\right) \cdot \cos \gamma \\
\left(\mathrm{R}-\mathrm{h}_{\mathrm{o}}-\mathrm{h}_{\mathrm{p}} \cdot \tan \gamma\right) \cdot \sin \gamma
\end{array} \\
& \mathrm{G}\left|\begin{array}{l}
\mathrm{R} \cdot \cos \left(\frac{\pi}{2}-\frac{\Gamma}{2}-\theta\right)=\mathrm{R} \cdot \sin \left(\frac{\Gamma}{2}+\theta\right) \\
-\mathrm{R} \cdot \cos \left(\frac{\Gamma}{2}+\theta\right)
\end{array}\right| \begin{array}{l}
\left(\mathrm{R}-\mathrm{h}_{\mathrm{o}}-\mathrm{h}_{\mathrm{p}} \cdot \tan \gamma\right) \cdot \cos \gamma \\
\mathrm{y}_{\mathrm{F}}
\end{array}
\end{aligned}
$$

F belongs to the straight line of slope $\tan \theta$ passing through $G$, hence the ordinate $\mathrm{yF}_{\mathrm{F}}$ verifies:

$$
\mathrm{y}_{\mathrm{F}}+\mathrm{R} \cdot \cos \left(\frac{\Gamma}{2}+\theta\right)=\tan \theta \cdot\left[\left(\mathrm{R}-\mathrm{h}_{\mathrm{o}}-\mathrm{h}_{\mathrm{p}} \cdot \tan \gamma\right) \cdot \cos \gamma-\mathrm{R} \cdot \sin \left(\frac{\Gamma}{2}+\theta\right)\right]
$$

Lastly, as $\mathrm{h}_{\text {fall }}=\mathrm{y}_{\mathrm{A}}-\mathrm{y}_{\mathrm{F}}$, the length of fall in a straight cross-section of the rotary kiln with partial hold-up is:

$$
\mathrm{h}_{\text {fall }}=\left(\mathrm{R}-\mathrm{h}_{\mathrm{o}}\right) \cdot \sin \gamma+\mathrm{h}_{\mathrm{p}} \cdot \cos \gamma+\mathrm{R} \cdot \cos \left(\frac{\Gamma}{2}+\theta\right)-\tan \theta \cdot\left[\left(\mathrm{R}-\mathrm{h}_{\mathrm{o}}-\mathrm{h}_{\mathrm{p}} \cdot \tan \gamma\right) \cdot \cos \gamma-\mathrm{R} \cdot \sin \left(\frac{\Gamma}{2}+\theta\right)\right]
$$




\section{FIGURES (main text)}

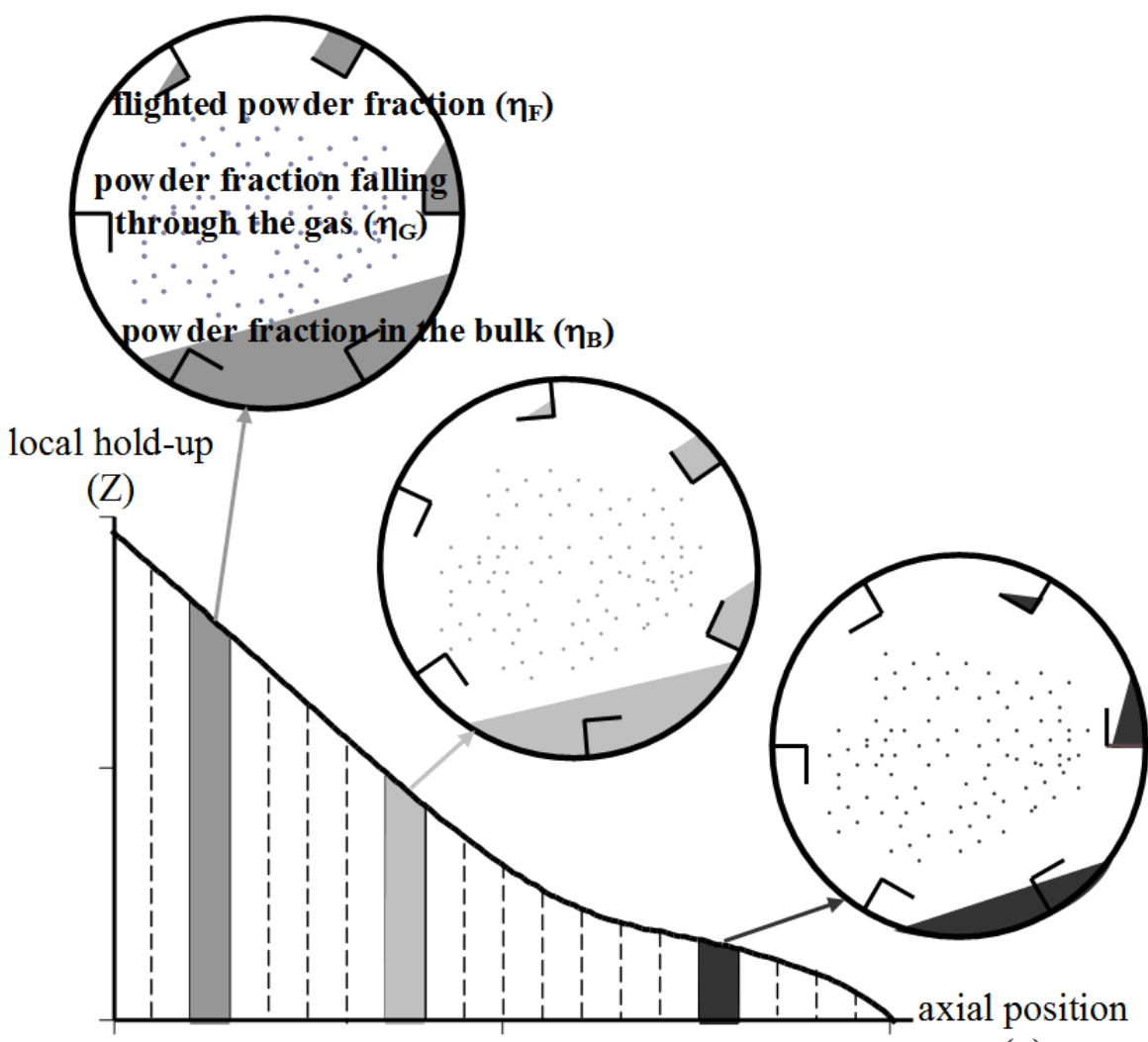

(x)

Fig. 0 / Graphical abstract. Axial and transverse distribution of cohesive powder in flighted rotary kilns used for the conversion of uranium.

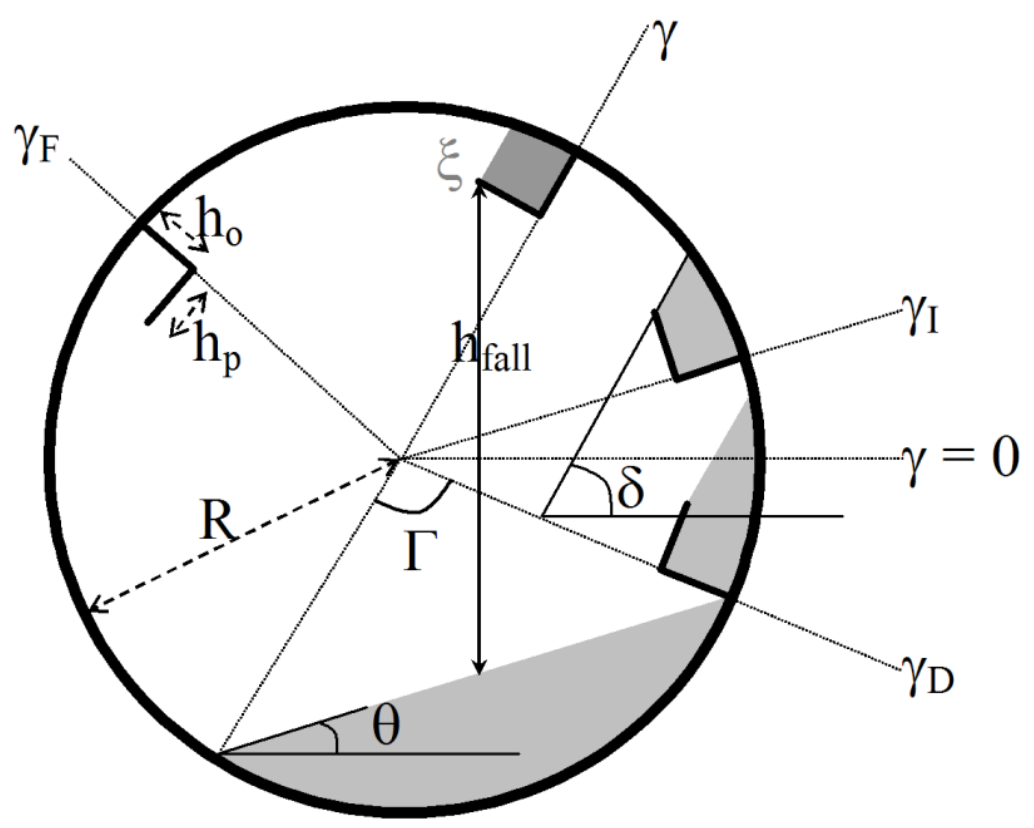

Fig. 1. Geometrical symbols used. 

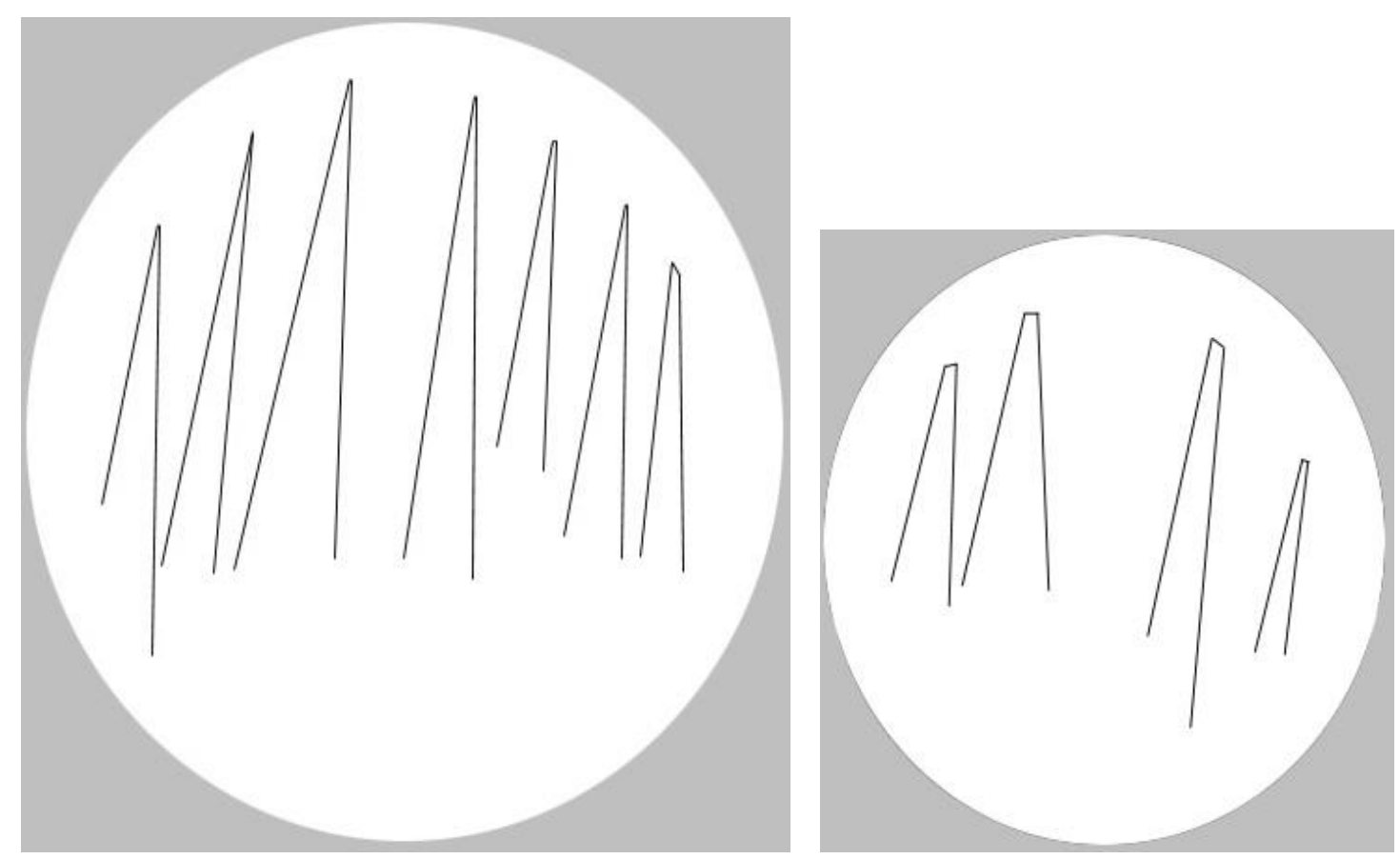

Fig. 2. Falling curtains from lifter tips at different angular positions overlaid on the same image: (a) $\mathrm{UO}_{2} \mathrm{~F}_{2}$ in drum $\# 1, \omega=3 \mathrm{rpm}$; (b) $\mathrm{UO}_{2}$ in drum $\# 2, \omega=5 \mathrm{rpm}$.

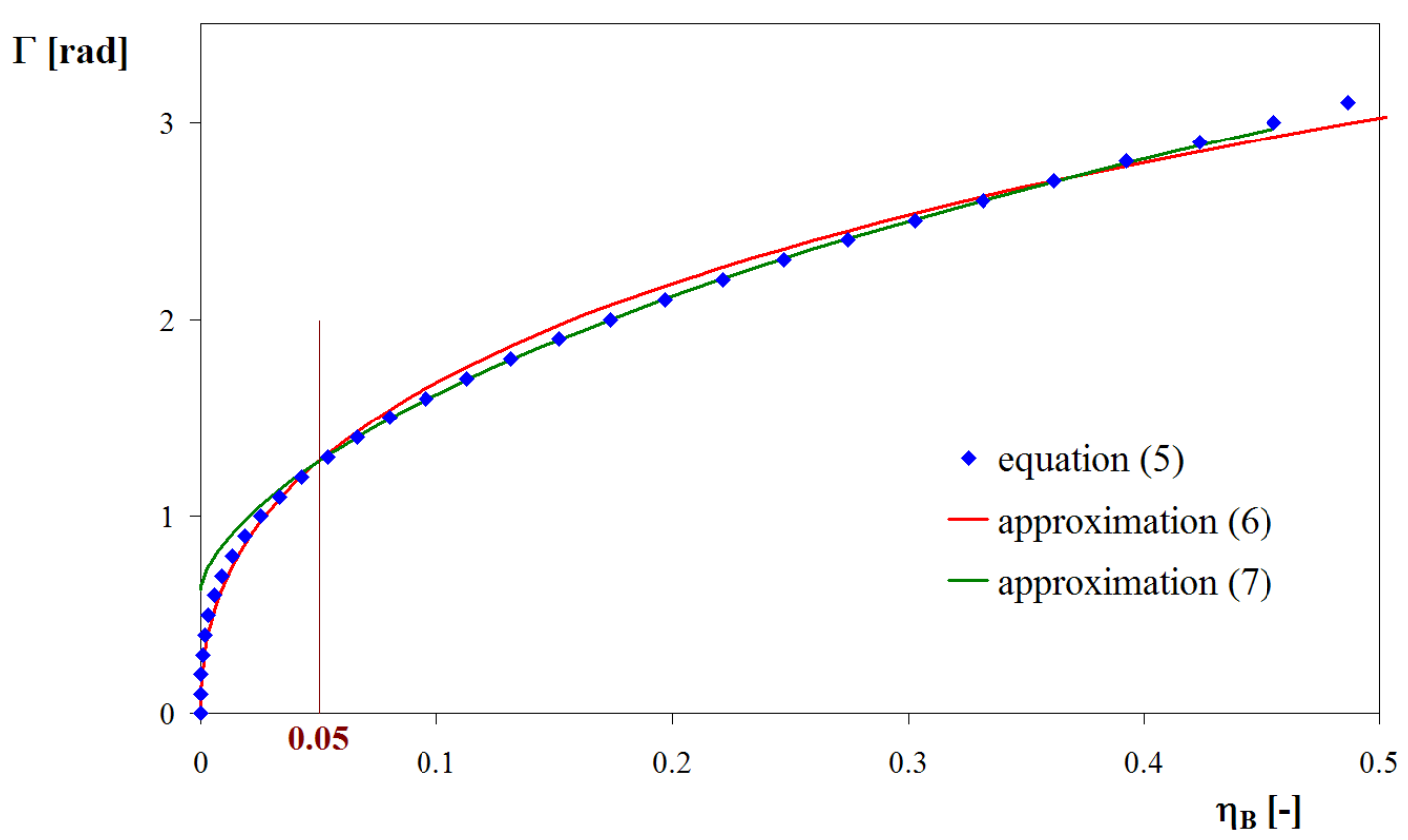

Fig. 3. $\Gamma$ versus $\eta_{\mathrm{B}}=\frac{\Gamma-\sin \Gamma}{2 \pi}$ and approximations of this equation.

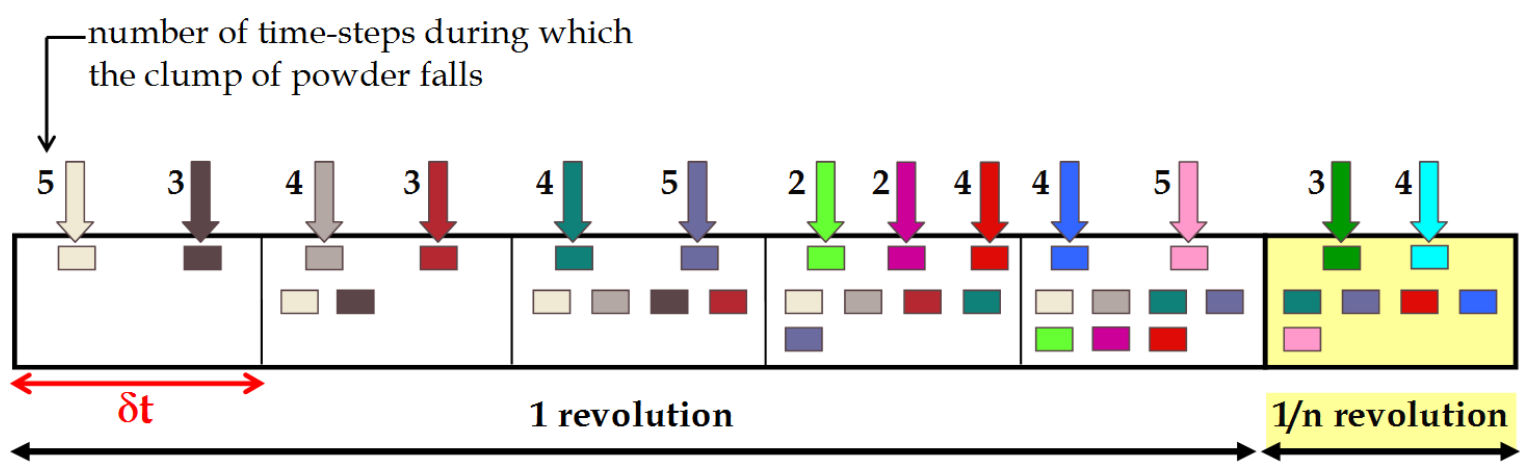

Fig. 4. Steps 3 and 4 of the procedure used to calculate the powder fraction $\eta_{G}$ falling through the gas at a given axial position (section 2.2.1). 


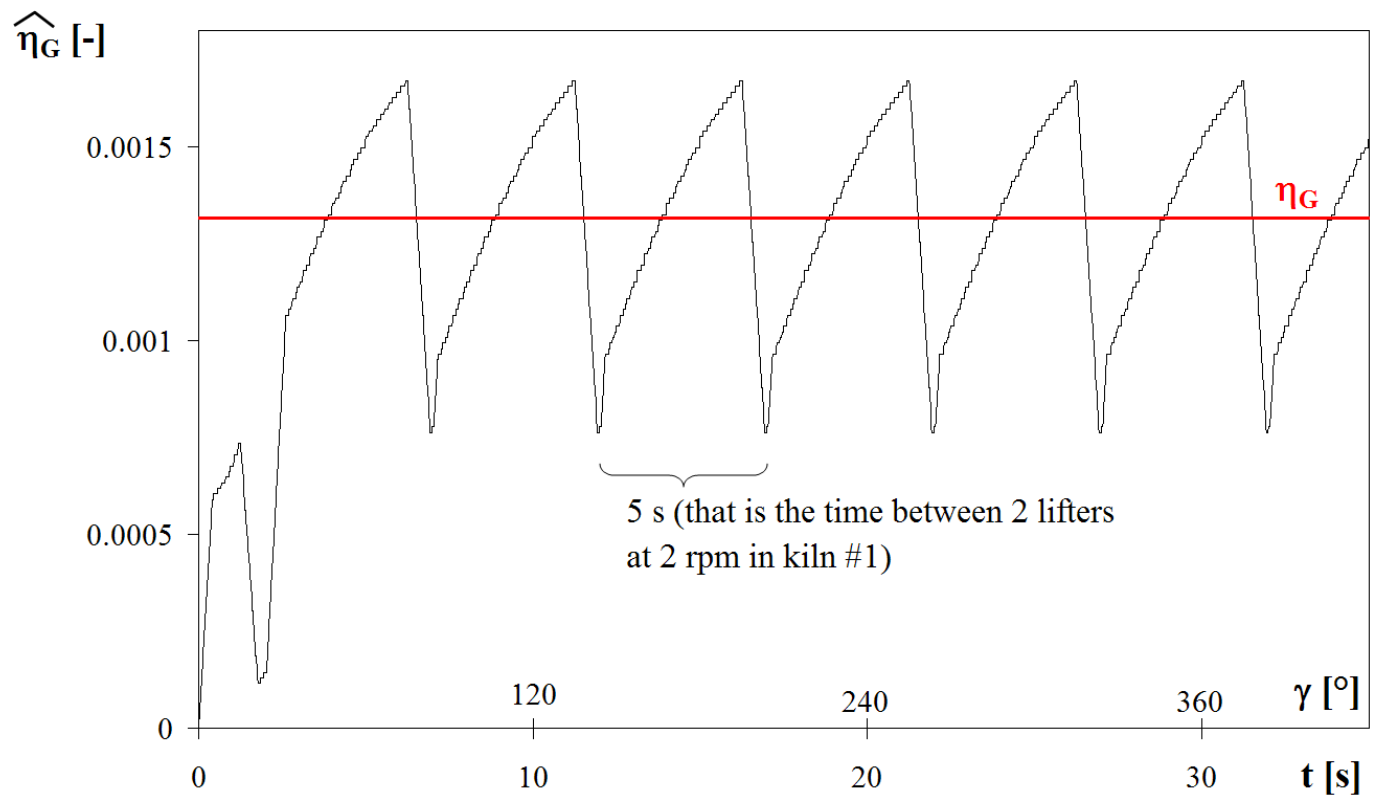

Fig. 5. Instantaneous powder fraction falling through the gas versus time during $1+1 / \mathrm{n}$ revolution $\left(\mathrm{UO}_{2} \mathrm{~F}_{2}\right.$ in kiln $\left.\# 1, \omega=2 \mathrm{rpm}\right)$.

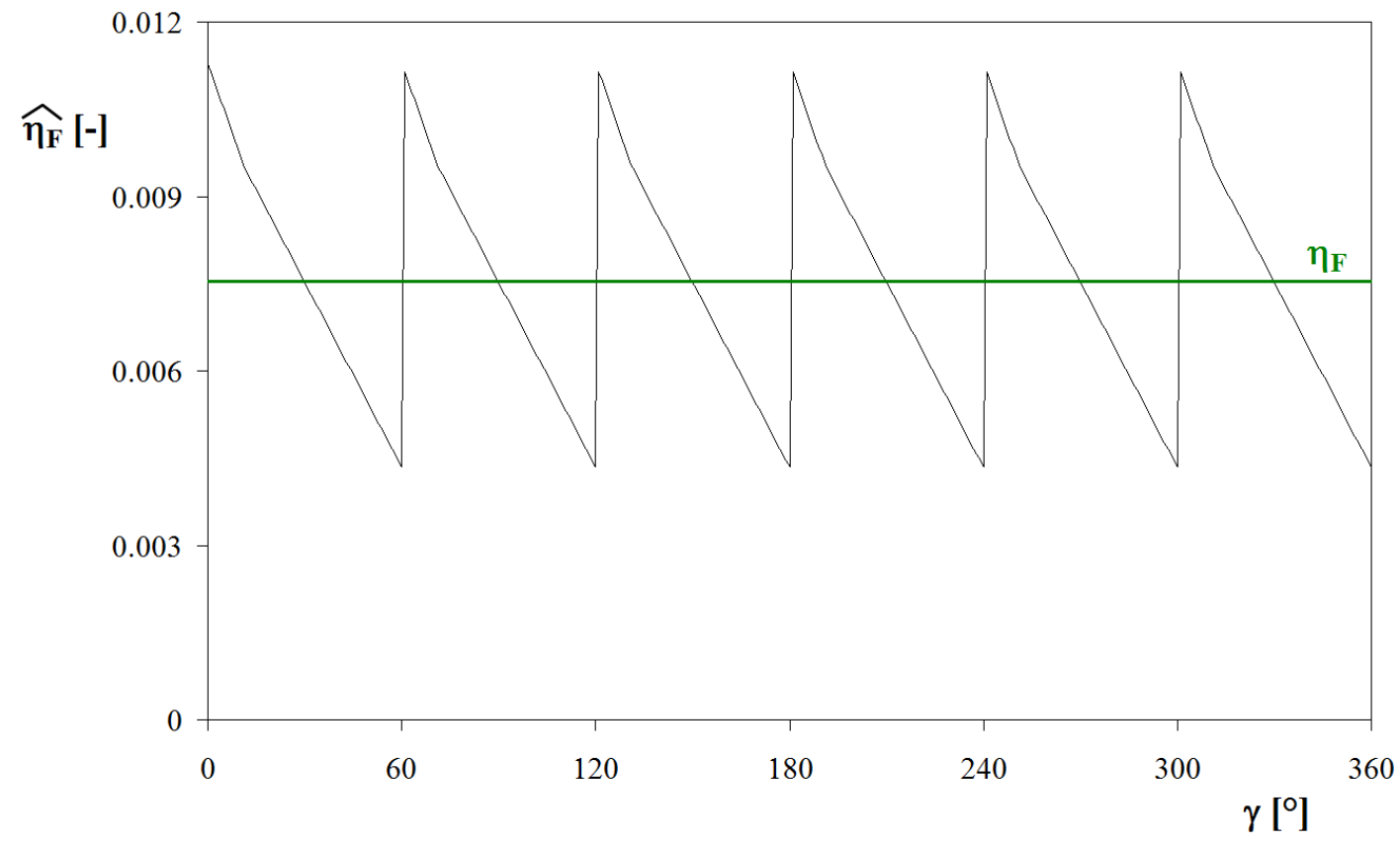

Fig. 6. Total flighted powder fraction versus angular position during one revolution $\left(\mathrm{UO}_{2} \mathrm{~F}_{2}\right.$ in kiln \#1). 

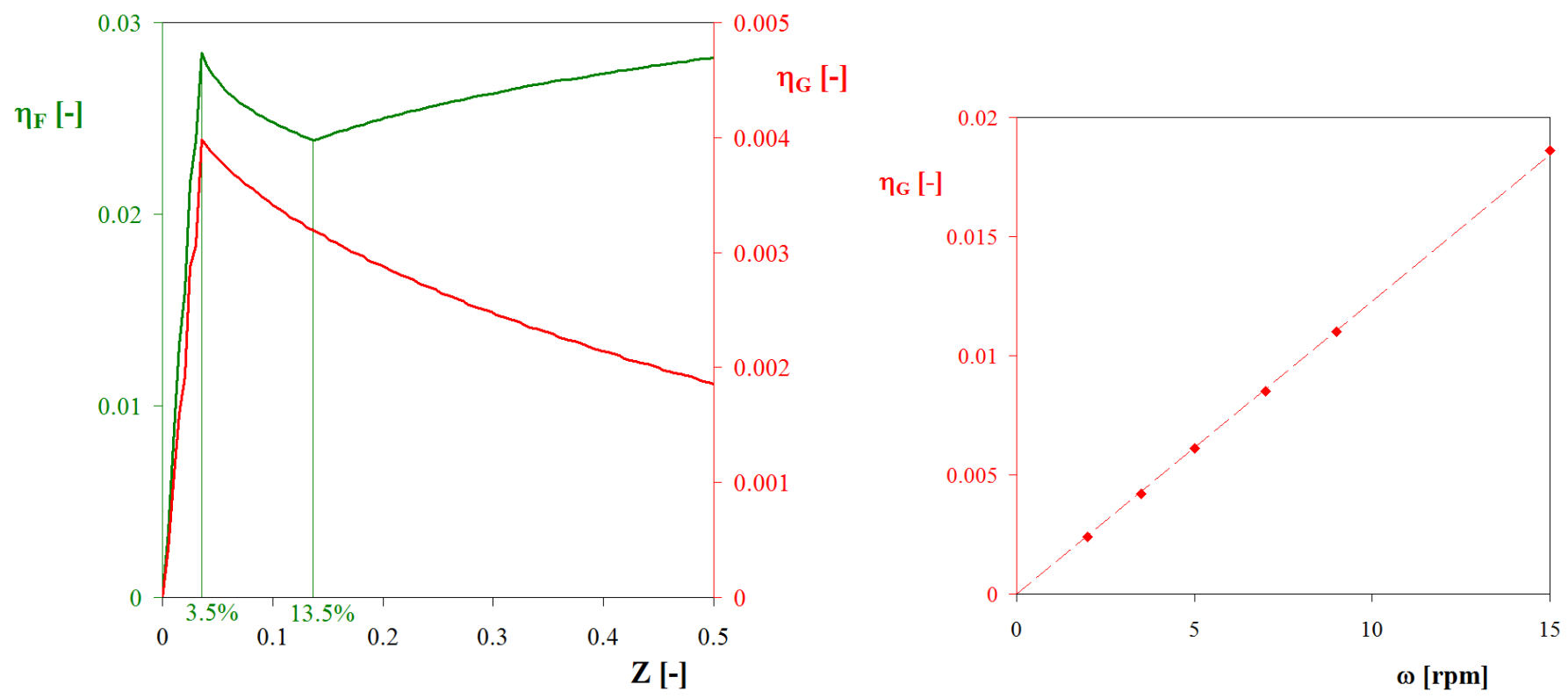

Fig. 7. (a) In green/black: flighted powder fraction versus hold-up; in red/grey: powder fraction falling through the gas versus hold-up $\left(\mathrm{U}_{3} \mathrm{O}_{8}\right.$, dimensions of kiln $\left.\# 2, \omega=7 \mathrm{rpm}\right)$. (b) Powder fraction falling through the gas versus rotational speed $\left(\mathrm{U}_{3} \mathrm{O}_{8}\right.$, dimensions of kiln $\left.\# 1, \mathrm{Z}=30,8 \%\right)$.

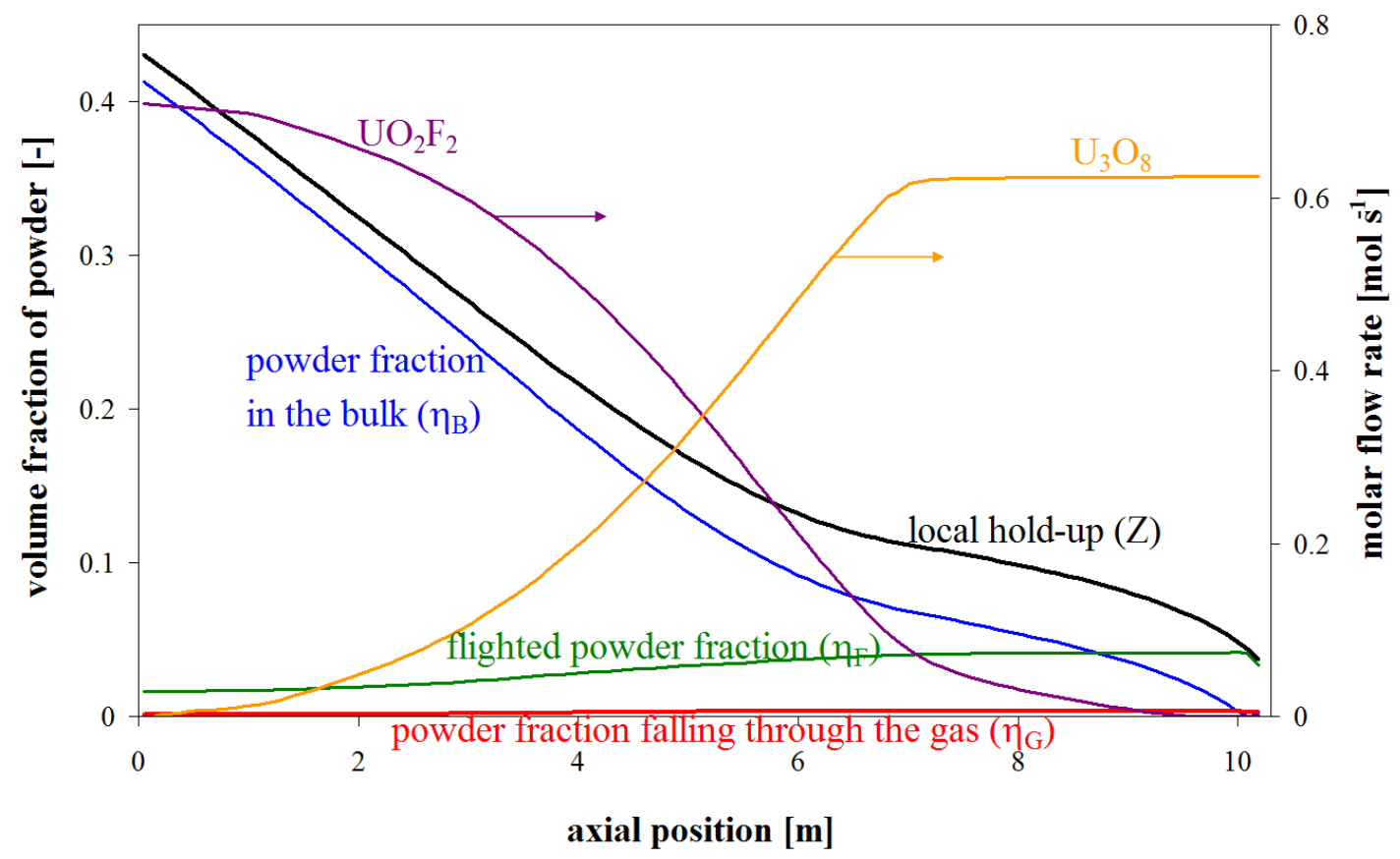

Fig. 8. Solid distribution in nominal operating conditions of kiln \#1; molar flow rates obtained from the mass transfer model (Debacq, 2001). 


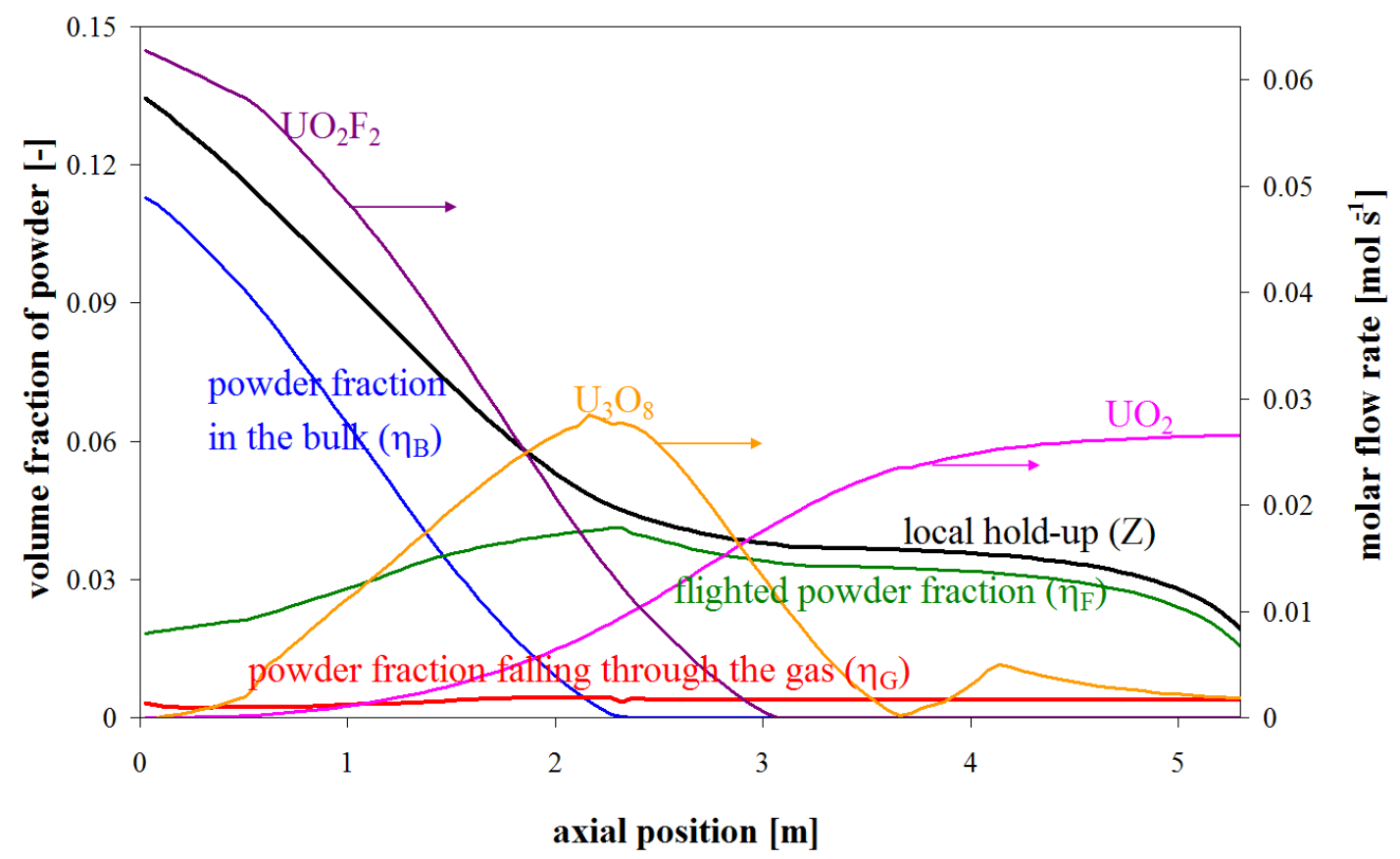

Fig. 9. Solid distribution in nominal operating conditions of kiln \#2; molar flow rates obtained from the mass transfer model (Debacq, 2001).

\section{FIGURE (appendix)}

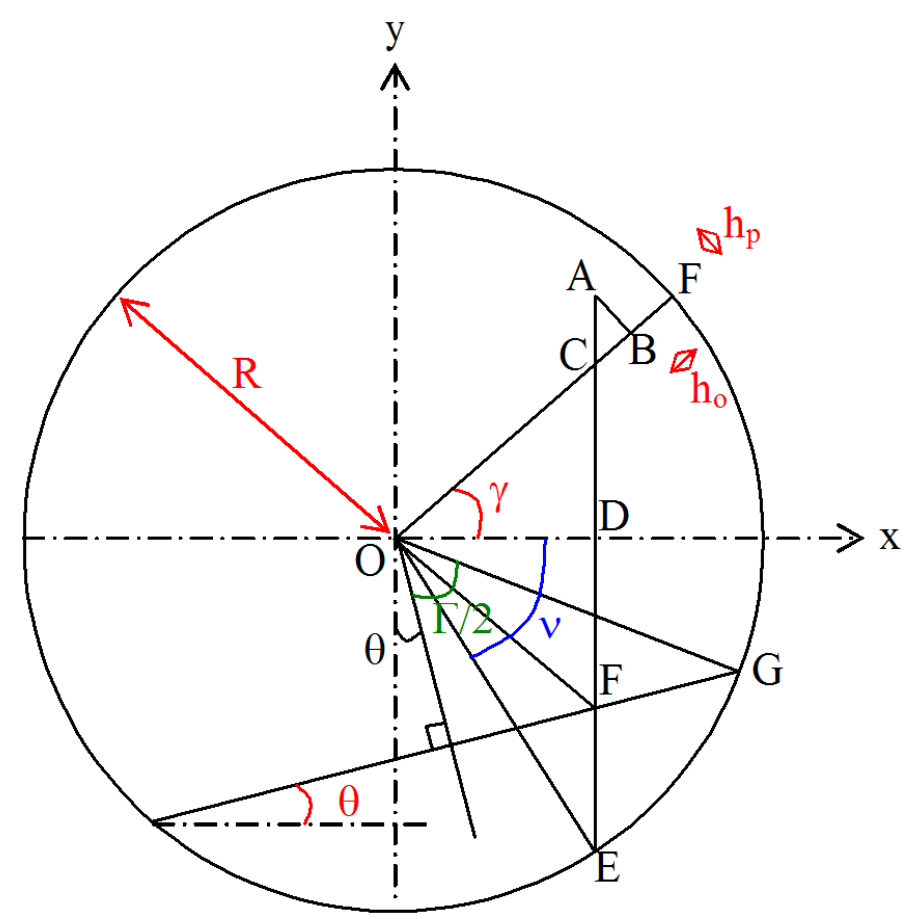

Fig. A. 1. Symbols used to calculate the length of fall. 


\section{TABLES}

Table 1. Nominal operating conditions of rotary kilns used.

\begin{tabular}{|c|c|c|}
\cline { 2 - 3 } \multicolumn{1}{c|}{} & kiln \#1 & kiln \#2 \\
\hline inside diameter & $750 \mathrm{~mm}$ & $348 \mathrm{~mm}$ \\
\hline length & $10.24 \mathrm{~m}$ & $5.34 \mathrm{~m}$ \\
\hline inclination & $2.5 \%$ & $2.5 \%$ \\
\hline number of lifters & 6 & 4 \\
\hline $\begin{array}{c}\text { lifter dimension normal to the } \\
\text { kiln wall }\end{array}$ & $60 \mathrm{~mm}$ & $35 \mathrm{~mm}$ \\
\hline $\begin{array}{c}\text { lifter dimension parallel to the } \\
\text { kiln wall }\end{array}$ & $60 \mathrm{~mm}$ & $35 \mathrm{~mm}$ \\
\hline UF flow rate & $860 \mathrm{~kg} / \mathrm{h}$ & $80 \mathrm{~kg} / \mathrm{h}$ \\
\hline $\mathrm{UO}_{2} \mathrm{~F}_{2}$ equivalent flow rate* & $753 \mathrm{~kg} / \mathrm{h}$ & $70 \mathrm{~kg} / \mathrm{h}$ \\
\hline counter-current $\mathrm{H}_{2} \mathrm{O}$ flow rate & $100 \mathrm{~kg} / \mathrm{h}$ & $18 \mathrm{~kg} / \mathrm{h}$ \\
\hline counter-current $\mathrm{H}_{2}$ flow rate & $18 \mathrm{Nm}^{3} / \mathrm{h}$ & $12 \mathrm{Nm} / \mathrm{h}$ \\
\hline final product of reactions & $\mathrm{U}_{3} \mathrm{O}_{8}$ & $\mathrm{UO} 2$ \\
\hline rotational speed & $2 \mathrm{rpm}$ & $7 \mathrm{rpm}$ \\
\hline heat devices temperatures & $750 ; 900 ; 900 ; 780{ }^{\circ} \mathrm{C}$ & $700 ; 730 ; 740 ; 710 ; 650 ; 630{ }^{\circ} \mathrm{C}$ \\
\hline
\end{tabular}

* At the entry of the conversion process, $\mathrm{UF}_{6}$ is instantaneously and completely converted to $\mathrm{UO}_{2} \mathrm{~F}_{2}$ in powder form; the " $\mathrm{UO}_{2} \mathrm{~F}_{2}$ equivalent flow rate" is therefore calculated from the flow rate of $\mathrm{UF}_{6}$ and the respective molecular masses of $\mathrm{UF}_{6}$ and of $\mathrm{UO}_{2} \mathrm{~F}_{2}$.

Table 2. Properties of the different powders.

\begin{tabular}{|l|c|c|c|c|}
\cline { 2 - 5 } \multicolumn{1}{c|}{} & $\mathbf{U O}_{2} \mathbf{F}_{\mathbf{2}}$ & $\mathbf{U}_{\mathbf{3}} \mathbf{O}_{\mathbf{8}}$ type \#1 & $\mathbf{U}_{\mathbf{3}} \mathbf{O}_{\mathbf{8}}$ type \#2 & $\mathbf{U O}_{\mathbf{2}}$ \\
\hline bulk density $\left[\mathrm{kg} \mathrm{m}^{-3}\right]$ & 380 & 1140 & 590 & 800 \\
\hline consolidated bulk density $\left[\mathrm{kg} \mathrm{m}^{-3}\right]$ & 470 & 2000 & 960 & 1630 \\
\hline grain size distribution $[\mu \mathrm{m}]$ & $20 \& 300$ & $10 \& 40$ & $3 \& 60$ & $3 \& 60$ \\
\hline static angle of repose $\left[{ }^{\circ}\right]$ & 43 & 50 & 51 & 45 \\
\hline dynamic angle of repose $\left[{ }^{\circ}\right]$ & $42 \pm 11$ & $33 \pm 8$ & $39 \pm 3$ & $33 \pm 13^{\circ}$ \\
\hline Carr's index $[-]$ & 0.2 & 0.4 & 0.4 & 0.5 \\
\hline Hausner ratio $[-]$ & 1.2 & 1.8 & 1.6 & 2.0 \\
\hline
\end{tabular}

The densities are measured by the method of the test tube $(250 \mathrm{~mL}$; inside diameter $39 \mathrm{~mm})$. They are obtained \pm $20 \mathrm{~kg} \mathrm{~m}^{-3}$.

The particle size distributions of samples of oxides $\left(\mathrm{U}_{3} \mathrm{O}_{8}\right.$ and $\left.\mathrm{UO}_{2}\right)$ were measured with a COULTER 1.311 .8 in water. $\mathrm{UO}_{2} \mathrm{~F}_{2}$ particle size distributions are measured in a COULTER 2.002 .2 in chloroform (powder highly soluble in water). The values given in the table are the mean sizes corresponding to main peaks (bimodal distributions).

The static angle of repose is measured using the crumbling cone method (NF T 20-221 standard): on a cone of powder formed using a calibrated funnel ( $92.9 \mathrm{~mm}$ larger diameter; $15.0 \mathrm{~mm}$ smaller diameter; $107 \mathrm{~mm}$ high); the funnel is in non-magnetic metal of surface roughness $0.16 \mu \mathrm{m}$.

The dynamic angles of repose for the four powders were measured by the rotating cylinder technique, using drums without lifting devices; its diameter is the same as in the corresponding industrial kiln; the length is $0.3 \mathrm{~m}$.. Sixteen experiments were performed, with hold-up ranging between $7.5 \%$ and $16 \%$ and rotational speed from 2 to $10 \mathrm{rpm}$. Each experiment was filmed for about two minutes after reaching steady state and one image every five seconds was extracted for analysis. The dynamic angles of repose were measured from the images using specific software (Debacq et al., 2013). 